\title{
IDENTIFIKASI PERSONAL HYGIENE DENGAN KEJADIAN KEPUTIHAN PADA PEMULUNG WANITA
}

\author{
PENY ARIANI ${ }^{1,}$ JULI FRANSISKA TUMANGGOR ${ }^{2}$
}

\author{
INSTITUT KESEHATAN DELI HUSADA DELI TUA \\ JL.BESAR NO. 77 DELI SERDANG-SUMATERA UTARA 20355 \\ FAKULTAS KEBIDANAN \\ Email : penyariani@gmail.com
}

DOI: https://doi.org/10.35451/jkk.v1i2.122

\begin{abstract}
Leucorrhoea is a condition of the vagina when removing fluid or mucus that resembles pus. Leucorrhoea is not always a disease because there is also normal vaginal discharge. Poor personal hygiene cause vaginal discharge. The purpose of this study was to determine the relationship between personal hygiene and vaginal discharge problems in female scavenger in the Landfills Tadukan Raga STM Hilir 2018. The type of research used was descriptive research with a cross sectional approach, namely an analytical survey. The sample of this study amounted to 23 respondents using total sampling. The data analysis was carried out by univariate and bivariate with Chi Square statistic test with a significance limit (a) of 0,05. The reseach showed that the majority of scavenger mothers had good skin hygiene, and good hand and nail hygiene as many as 13 people with a percentage (56,5\%), and having poor Genetalia Hygiene as many as 13 people with a percentage (56,5\%). The conclusion there is no relationship between skin hygiene and vaginal discharge ( $\rho=0,341$ ), there is no relationship between hand and nail hygiene with vaginal discharge $(\rho=0,660)$, and there is a correlation between genetalia hygiene and vaginal discharge in scavenger mothers $(\rho=0,019)$. Skin hygiene, hand and nail hygiene are not entirely a factor causing vaginal discharge problems, there are still many other causal factors which are the limitations of this study, while genetalia hygiene greatly affects the occurrence of vaginal discharge problems.
\end{abstract}

Keywords: Leucorrhoea, Personal Hygiene, Female Scavenger

\section{PENDAhuluan}

Prevalensi keputihan sendiri sebesar 28,99\% lebih banyak ditemukan pada kelompok usia yang lebih muda, buta huruf, perempuan yang memiliki status sosial ekonomi rendah dan mereka yang menikah kurang dari usia 18 tahun (Guntoory, Tamaraba, Nambaru, \& Kalavakuri, 2017).

Berdasarkan penelitian Dagasou, Pondaag (2014) sebanyak $75 \%$ wanita di dunia akan mengalami keputihan sekali seumur hidup dan mengalami keputihan dua kali atau lebih seumur hidup sebanyak $45 \%$. Angka keputihan pada kaum wanita yang berada dieropa sebesar 25\%, dimana 40-50 \% akan mengalami kekambuhan (Dagasou, dkk. 2014).

Indonesia merupakan daerah beriklim tropis, sehingga pertumbuhan jamur bisa lebih cepat, sehingga 90\% wanita di Indonesia beresiko mengalami keputihan (Qomariyah, 2001). 
Kebersihan lingkungan dan jasmani sangat menentukan derajat kesehatan masyarakat, terutama paparan zat kimia berbahaya yang dihasilkan lingkungan dapat berpengaruh besar terhadap kesehatan (Baar, Romppel, Igel, \& Brähler, 2016). Berdasarkan hasil penelitian Morsi et al. (2017) Pemulung memiliki resiko yang lebih besar mengalami gangguan kesehatan dari berbagai system organ akibat paparan lingkungan yang buruk selama bekerja. Gangguan kesehatan yang beresiko terjadi adalah, gangguan system pernafasan, system perkemihan, system pencernaan serta system reproduksi.

Kejadian infeksi saluran reproduksi sangat beresiko apabila pengetahuan dan perilaku dalam kebersihan alat reproduksi tidak baik. Infeksi saluran reproduksi yang berkepanjangan akan menyebabkan penyakit antara lain, vulvitis, vaginitis, keputihan, vulvovaginitis dan sampai kanker servik. (Wardani, 2012).

Berdasarkan penelitian Rahayu, Rika Puji; Damayanti, Fitriani Nur; Purwanti (2015) Ada hubungan yang bermakna antara pekerjaan dengan keputihan pada wanita usia subur (dengan $p$ value $=0,001>0,05) /$ $\mathrm{OR}=10$, dengan kata lain bahwa wanita yang bekerja sebagai pemulung akan memiliki resiko 10 kali lebih besar mengalami keputihan karena kondisi lingkungan kerja yang buruk.

Berdasarkan survey awal yang dilakukan di TPA Tadukan raga STM Hilir, bahwa beberapa ibu bekerja sebagai pengumpul barang-barang bekas dan beberapa ibu yang membantu suaminya, dari hasil wawancara yang dilakukan oleh peneliti pada beberapa ibu kurang memperhatikan kebersihan organ genitalia serta 7 dari 10 ibu pernah mengalami keputihan selama bekerja sebagai pemulung.

\section{METODE}

Penelitian ini merupakan jenis Penelitian deskriptif dengan pendekatan cross sectional untuk mengetahui hubungan personal hygiene dengan masalah keputihan pada ibu pemulung di TPA Tadukan Raga STM Hilir tahun 2018. Populasi penelitian ini adalah seluruh ibu pemulung yang ada di TPA Tadukan Raga STM Hilir. Sampel dalam penelitian ini berjumlah 23 orang yang diambil dengan menggunakan teknik total sampling dari seluruh anggota pemulung yang berjenis kelamin wanita. Alat ukur dalam penelitian ini menggunakan kuisioner valid yang memuat tentang personal hygiene untuk mengumpulkan data tentang personal hygiene wanita pemulung. Data yang sudah di entri selanjutnya dinarasikan dalam bentuk table dan dianalisa secara deskriptif untuk menggambarkan personal hygiene wanita pemulung di TPA Tadukan raga STM Hilir.

\section{HASIL}

\section{Karakteristik Responden}

Tabel 3.1. Distribusi Karakteristik Responden di TPA Tadukan Raga STM Hilir Tahun 2018.

\begin{tabular}{lcc}
\hline \multicolumn{1}{c}{ Karakteristik } & $\mathrm{n}$ & $\begin{array}{c}\text { Persentase } \\
(\%)\end{array}$ \\
\hline Umur & & \\
30-35 Thn & 7 & 30,4 \\
36-40 Thn & 10 & 43,5 \\
$>$ 40 Thn & 6 & 26,1 \\
\hline Agama & & \\
Islam & 18 & 78,3 \\
Protestan & 5 & 21,7 \\
\hline Pendidikan & & \\
Tidak Sekolah & 2 & 8,7 \\
Tamat SD & & \\
Tamat SMP & 13 & 56,6 \\
Tamat SMA & 7 & 30,4 \\
& 1 & 4,3 \\
\hline
\end{tabular}


Jurnal Kebidanan Kestra (JKK), e-ISSN: 2655-0822

Vol. 1 No.2 Edisi November 2018 -April 2019

http://ejournal.medistra.ac.id/index.php/JKK

$==================================================+$
Received: 27 April 2019 :: Accepted: 27 April 2019 :: Published 29 April 2019

\begin{tabular}{lcc}
\hline Lama bekerja & & \\
5-15 Thn & 7 & 30,4 \\
16-20 Thn & 4 & 17,4 \\
21-26 Thn & 5 & 21,7 \\
27-31 Thn & 6 & 26,2 \\
> 31 Thn & 1 & 4,3 \\
\hline Waktu bekerja & & \\
< 8 Jam & 7 & 30,4 \\
> 8 Jam & 16 & 69,6 \\
\hline \multicolumn{1}{c}{ Total } & 23 & 100,0 \\
\hline
\end{tabular}

\begin{tabular}{lcc}
\hline Baik & 13 & 56,5 \\
Buruk & 10 & 43,5 \\
\hline Genitalia & & \\
Baik & 10 & 43,5 \\
Buruk & 13 & 56,5 \\
\hline Total & 23 & 100,0 \\
\hline
\end{tabular}

Berdasarkan tabel 3.2. Menunjukkan bahwa mayoritas responden yang memiliki Kebersihan kulit yang Baik yaitu sebanyak 13 orang dengan persentase $(56,5 \%)$, mayoritas

Berdasarkan tabel 3.1. Distribusi Frekuensi Mayoritas Umur responden adalah Berumur 36-40 Thn yaitu sebanyak 10 orang dengan persentase $(43,5 \%)$, mayoritas Agama Responden adalah beragama Islam sebanyak 18 orang dengan persentase (78,3\%), mayoritas Pendidikan Responden adalah tamat SD sebanyak 13 orang dengan persentase $(6,6 \%)$, mayoritas Lama bekerja Responden adalah 5-15 Thn sebanyak 7 orang dengan persentase $(30,4 \%)$, dan mayoritas Waktu bekerja Responden adalah $>8$ jam sebanyak 16 orang dengan persentase $(69,6 \%)$.

\section{Analisis Univariat Personal Hygiene \\ a. Kebersihan Kulit Pemulung Wanita}

Tabel 3.2. Distribusi Frekuensi personal hygiene Pemulung wanita di TPA Tadukan Raga STM Hilir Tahun 2018.

\begin{tabular}{lcc}
\hline Personal Hygiene & $\mathrm{n}$ & $\begin{array}{c}\text { Persentase } \\
(\%)\end{array}$ \\
\hline Kulit & & \\
Baik & 13 & 56,5 \\
Buruk & 10 & 43,5 \\
\hline Tangan dan Kuku & & \\
\hline
\end{tabular}
Tangan dan Kuku yang Baik yaitu sebanyak 13 orang dengan persentase $(56,5 \%)$, dan mayoritas responden yang memiliki Kebersihan Genetalia yang Buruk yaitu sebanyak 13 orang dengan persentase $(56,5 \%)$.

\section{b. Keputihan Pada Pemulung}

Tabel 3.3. Distribusi Frekuensi Keputihan Pada Pemulung Wanita di TPA Tadukan Raga STM Hilir Tahun 2018.

\begin{tabular}{ccc}
\hline Keputihan & $\mathrm{n}$ & $\begin{array}{c}\text { Persentase } \\
(\%)\end{array}$ \\
\hline $\begin{array}{c}\text { Mengalami } \\
\text { Keputihan } \\
\text { Tidak Mengalami } \\
\text { Keputihan }\end{array}$ & 6 & 26,1 \\
\hline Total & 23 & 100,0 \\
\hline
\end{tabular}

Berdasarkan tabel 3.3. Menunjukkan bahwa mayoritas responden yang tidak mengalami Keputihan yaitu sebanyak 15 orang dengan persentase $(65,2 \%)$, dan minoritas responden yang mengalami Keputihan yaitu sebanyak 8 orang dengan persentase $(34,8 \%)$. 


\section{Analisis Bivariat}

a. Kebersihan Kulit Dengan Masalah Keputihan

Tabel 3.4. Tabel silang Hubungan antara Kebersihan kulit dengan Masalah Keputihan Pada Ibu Pemulung di TPA Tadukan Raga STM Hilir Tahun 2018.

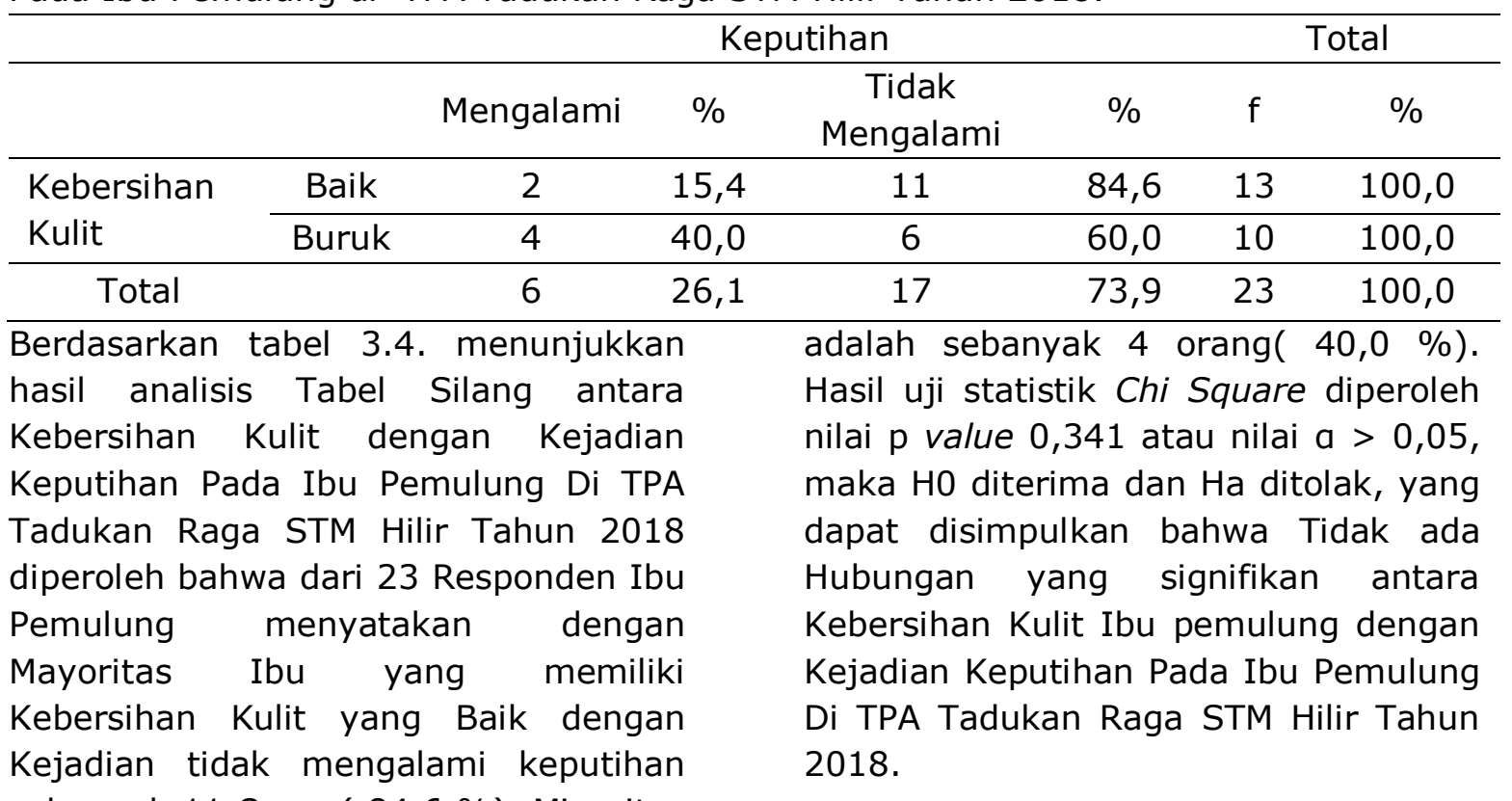
sebanyak 11 Orang( $84,6 \%$ ), Minoritas Ibu dengan status Kebersihan Kulit yang Buruk mengalami Keputihan

\section{b. Kebersihan Tangan dan Kuku dengan Masalah Keputihan}

Tabel 3.5. Tabel silang Hubungan antara Kebersihan Tangan dan Kuku dengan Masalah Keputihan Pada Ibu Pemulung di TPA Tadukan Raga STM Hilir Tahun 2018.

\begin{tabular}{cccccccc}
\hline & \multicolumn{9}{c}{ Keputihan } & \multicolumn{2}{c}{ Total } \\
\hline & Mengalami & $\%$ & $\begin{array}{c}\text { Tidak } \\
\text { Mengalami }\end{array}$ & $\%$ & $\mathrm{f}$ & $\%$ \\
\hline $\begin{array}{l}\text { Kebersihan } \\
\text { tangan dan } \\
\text { kuku }\end{array}$ & Baik & 4 & 30,8 & 9 & 69,2 & 13 & 100,0 \\
\cline { 2 - 8 } \multicolumn{1}{c}{ Total } & Buruk & 2 & 20,0 & 8 & 80,0 & 10 & 100,0 \\
\hline
\end{tabular}

Berdasarkan tabel 3.5. menunjukkan hasil analisis Tabel Silang antara Kebersihan Tangan dan Kuku dengan Kejadian Keputihan Pada Ibu Pemulung Di TPA Tadukan Raga STM Hilir Tahun 2018 diperoleh bahwa dari 23 Responden Ibu Pemulung menyatakan dengan Mayoritas Ibu yang memiliki Kebersihan Tangan dan Kuku yang Baik dengan tidak mengalami kejadian keputihan sebanyak 9 Orang $(69,2 \%)$, Minoritas Ibu dengan status Kebersihan Tangan dan Kuku yang Buruk mengalami Keputihan adalah 2 orang $(20,0 \%)$. Hasil uji statistik Chi Square diperoleh nilai $p$ value 0,660 atau nilai a $>0,05$, maka $\mathrm{HO}$ diterima dan $\mathrm{Ha}$ ditolak, yang dapat disimpulkan bahwa Tidak ada Hubungan yang signifikan antara Kebersihan Tangan dan Kuku Ibu pemulung dengan Kejadian Keputihan Pada Ibu Pemulung Di TPA Tadukan Raga STM Hilir Tahun 2018. 


\section{c. Kebersihan Genetalia dengan Masalah Keputihan}

Tabel 3.6. Tabel silang Hubungan antara Kebersihan Genetalia dengan Masalah Keputihan Pada Pemulung Wanita di TPA Tadukan Raga STM Hilir Tahun 2018.

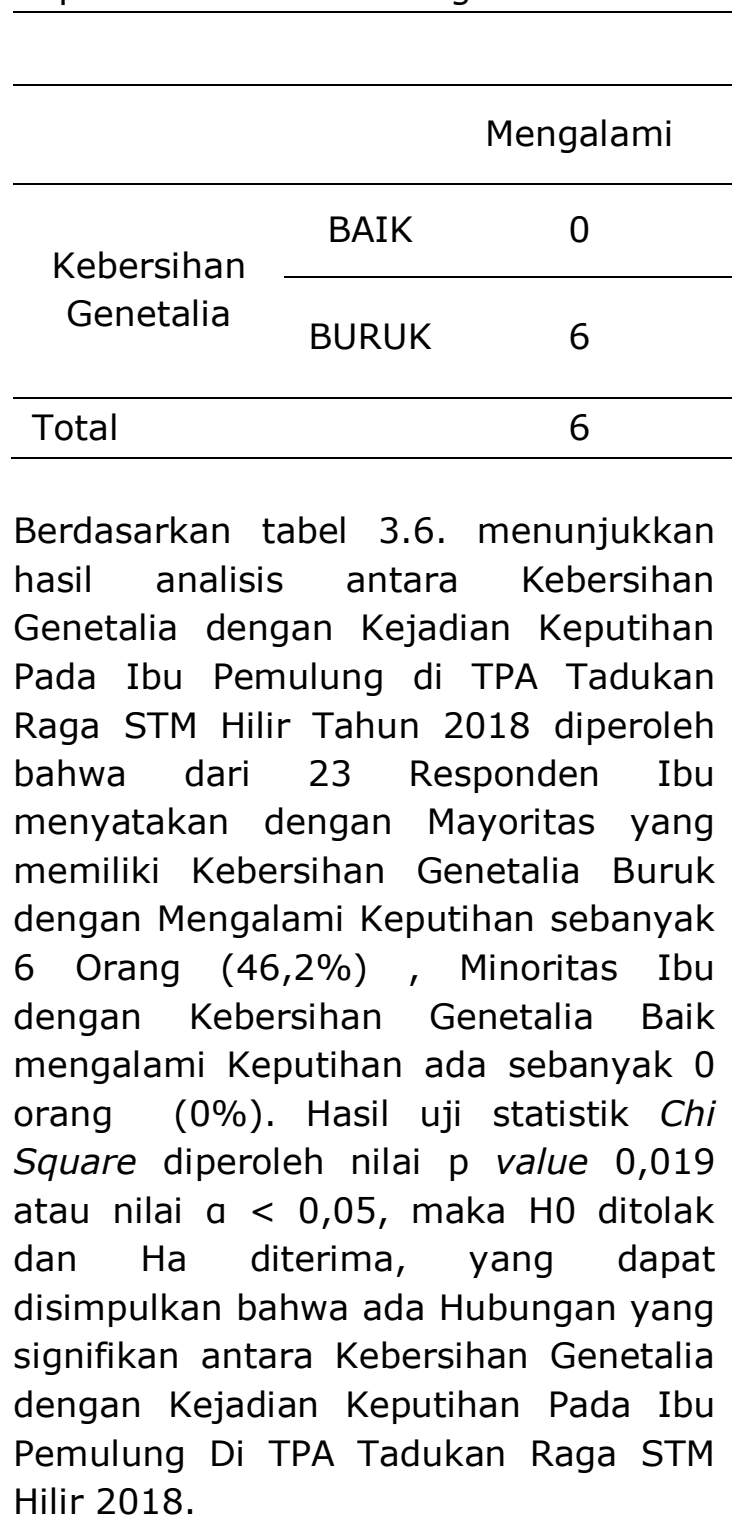

4. Pembahasan

a. Hubungan Kebersihan Kulit Dengan Masalah Keputihan Pada Ibu pemulung

Dari hasil diatas peneliti menyimpulkan bahwa ibu pemulung memiliki personal hygiene yang baik tidak mengalami keputihan, disisi lain banyak teori mengatakan bahwa keputihan terjadi bukan hanya dari personal hygiene yang buruk saja tapi dapat dipengaruhi dari status gizi,
Total

Keputihan

Tidak Mengalami

$\% \quad f \quad \%$

$\begin{array}{lllll}0,0 & 10 & 100,0 & 10 & 100,0\end{array}$

46,2

7

$58,3 \quad 13 \quad 100,0$

26,1

17

73,9

23100,0

berat badan, pola makan yang tidak teratur, stress dan masih banyak lagi. Pada saat peneliti melakukan wawancara dan membagikan kuisioner, peneliti mengamati kebersihan kulit dari ibu pemulung, terlihat bahwa kebersihan kulit ibu memang terlihat kurang bersih, namun setiap ibu pemulung kembali kerumah mereka wajib membersihkan diri mereka dengan baik, dapat disimpulkan bahwa mereka sangat memperhatikan kebersihan kulit mereka.

Berdasarkan jam kerja pemuluing wanita, maka pemulung biasanya mandi di pagi hari sebelum bekerja dan mandi sore dilakukan setelah sampai kerumah, namun banyak pemulung yang tidak langsung mengganti pakaian ketika sampai dirumah karena melaksanakan tugas rumah terlebih dahulu, hal ini yang sering menyebabkan pemulung wanita mengalami gatal-gatal dan gangguan kulit lainnya (Srikanti, 2018).

Pemulung wanita juga beresiko mengalami gangguan kulit karena terpajan kuman lebih lama dengan waktu bekerja rerata 8 jam. Hal ini akan berdampak terhadap kesehatan pemulung wanita sehingga kebersihan kulit sangat berhubungan dengan gangguan kesehatan wanita (Ferusgel, Nasution, \& Butar-butar, 2018). 


\section{b. Hubungan Kebersihan Tangan Dan Kuku dengan Masalah Keputihan Pada Ibu Pemulung}

Kebersihan tangan dan kuku pada ibu pemulung sangat berpotensi untuk media berpindahnya bakteri ke tubuh dan bagian tubuh yang terpapar oleh tangan dan kuku. Kebersihan tangan, kuku pada pemulung saat wawancara berdasarkan jawaban responden dapat dilihat bahwa ibu pemulung mencuci tangan dengan sabun sebelum dan sesudah makan, dan kuku mereka tidak selalu dalam keadaan bersih.

Berdasarkan observasi secara langsung, terlihat bahwa tangan, kuku kurang bersih. Dari hasil pengamatan bahwa kuku-kuku mereka tidak panjang namun berwarna hitam karena menggunakan sarung tangan yang sudah tidak layak pakai. Tangan, dan kuku yang kurang bersih akan mudah kuman penyakit masuk kedalam tubuh kita. Namun pada saat diwanwancarai mereka mengatakan setiap kembali kerumah mereka akan membersihkan kuku dan tangan dengan baik karena mereka akan melakukan aktifitas memasak jadi mereka memastikan kebersihan tangan dan kuku mereka harus tetap bersih.

Tangan memiliki flora normal yang bisa menyebabkan penyakit pada tubuh manusia jika masuk kedalam saluran pencernaan, pernafasan maupun reproduksi. Menurut penelitian Artika \& Alioes (2014), bahwa kebiasaan mencuci tangan dan memotong kuku yang buruk sangat berhubungan dengan kejadian giardiasis asimptomatik yang bisa mengganggu saluran pencernaan.

Selain itu, cara mencuci tangan yang baik juga harus dilakukan sesuai dengan standard WHO, untuk memperkecil transmisi kuman dan bakteri ke dalam tubuh manusia, apalagi pekerjaan Pemulung yang sangat rentan dengan paparan kuman dan bakteri melalui tangan dan kuku akan meningkatkan resiko pemulung untuk mengalami gangguan pencernaan, gangguan kulit, gangguan pernafasan serta gangguan reproduksi (Fitria, 2017).

\section{c. Hubungan Kebersihan Genitalia dengan Masalah Keputihan Pada Ibu Pemulung}

Keputihan merupakan masalah yang sering beresiko dialami oleh wanita. Namun masih banyak wanita yang memiliki pengetahuan yang kurang tentang keputihan dan penyebabnya. Beberapa ibu bekerja sebagai pengumpul barang-barang bekas dan beberapa ibu yang membantu suaminya, dari hasil wawancara yang dilakukan oleh peneliti pada beberapa ibu kurang memperhatikan kebersihan organ genitalia. Kurangnya perhatian terhadap kebersihan genetalia dapat menyebabkan keputihan pada ibu pemulung.

Sesuai dengan anatomi organ genitalia, bahwa vagina merupakan tempat terbuka dan jalan untuk masuknya bakteri kedalam Rahim, yang bisa menyebabkan innfeksi, baik dari bakteri yang ada di sekitar uretra maupun anus (Coad, Jane; Dunstall, 2011).

Hasil penelitian sesuai dengan penelitian Arismaya, Anggun Mita; Andayani, Ari; Diah (2016) dimana kebersihan genetalia yang buruk akan beresiko mengalami keputihan yang lebih tinggi. Genetalia yang memang merupakan organ intim yang memiliki flora normal akan bisa berdampak buruk jika kebersihannya tidak diperhatikan. Pemberian sabun saat membersihkan genetalia juga bisa membantu membunuh mikroorganisme didaerah genetalia sehingga bisa mencegah terjadinya keputihan. 


\section{KESIMPULAN}

Tidak ada Hubungan yang signifikan antara Kebersihan Kulit Ibu pemulung dengan Kejadian Keputihan Pada Ibu Pemulung Di TPA Tadukan Raga STM Hilir Tahun 2018, $a=0,05$ dengan nilai $\mathrm{p}=0,341$. Tidak Ada hubungan yang signifikan antara Kebersihan Tangan dan Kuku dengan masalah keputihan pada Ibu Pemulung di TPA Tadukan Raga Tahun 2018, $\mathrm{a}=$ 0,05 dengan nilai $\mathrm{p}=0,660$. Ada hubungan yang signifikan antara Kebersihan Genetalia dengan masalah keputihan pada Ibu Pemulung di TPA Tadukan Raga Tahun 2018 a = 0,05 dengan nilai $p=0,019$.

\section{DAFTAR PUSTAKA}

Arismaya, Anggun Mita; Andayani, Ari; Diah, M. (2016). Hubungan perawatan genetalia dengan kejadian keputihan pada santriwati pondok pesantren al iman sumowono kabupaten semarang. Jurnal Keperawatan Anak, 3, 3944.

Artika, M., \& Alioes, Y. (2014). Artikel Penelitian Hubungan Kebiasaan Mencuci Tangan dan Memotong Kuku dengan Kejadian Giardiasis Asimtomatik, 6(1), 70-75.

Baar, J., Romppel, M., Igel, U., \& Brähler, E. (2016). The association between physical environment and health: indicating the direction of effects using German panel data. International Journal of Occupational and Environmental Health, 22(1), 1-6. https://doi.org/10.1080/10773525 .2015.1106074

Coad, Jane; Dunstall, M. (2011). Anatomy and Physiology for Midwives (3rd ed.). Churchill Livingstone: Elsevier.

Dagasou, Pondaag, L. (2014). GAMBARAN TINGKAT
PENGETAHUAN IBU TENTANG KEPUTIHAN DI POLIKLINIK OBSTETRI/GINEKOLOGI RSU. PANCARAN KASIH GMIM MANADO TAHUN 2014. Ejournal Universitas Sam Ratulangi, 36. Retrieved from https://ejournal.unsrat.ac.id/index .php/jkp/article/view/5610/5144

Ferusgel, A., Nasution, R. M., \& Butarbutar, M. (2018). Jurnal Aisyah: Jurnal Ilmu Kesehatan Keluhan Gangguan Kulit pada Pemulung Wanita Di Tempat Pembuangan Akhir ( TPA ) Terjun, 3(2), 145152.

Fitria, M. (2017). Hubungan Higiene Perorangan dan Karakteristik Pemulung dengan Keluhan Gangguan Kulit di TPA Tandukan Raga Kecamatan STM Hilir Kabupaten Deli Serdang Tahun 2017.

Guntoory, I., Tamaraba, N. R., Nambaru, L. R., \& Kalavakuri, A. S. (2017). Prevalence and sociodemographic correlates of vaginal discharge among married women of reproductive age group at a teaching hospital, 6(11), 4840-4846.

Morsi, R. Z., Safa, R., Baroud, S. F., Fawaz, C. N., Farha, J. I., Eljardali, F., \& Chaaya, M. (2017). The protracted waste crisis and physical health of workers in Beirut: a comparative crosssectional study, 1-6. https://doi.org/10.1186/s12940017-0240-6

Qomariyah, S. N. (2001). Infeksi saluran reproduksi (ISR) pada perempuan Indonesia. Jakarta Overseas Office.

Rahayu, Rika Puji; Damayanti, Fitriani Nur; Purwanti, I. A. (2015). KELURAHAN ROWOSARI SEMARANG. Jurnal UNIMUS, 2-7.

Srikanti, L. (2018). Kehidupan Sosial Ekonomi dan Perilaku Pemulung di 
Jurnal Kebidanan Kestra (JKK), e-ISSN: 2655-0822

Vol. 1 No.2 Edisi November 2018 -April 2019

http://ejournal.medistra.ac.id/index.php/JKK

$===================================================$
Received: 27 April 2019 :: Accepted: 27 April 2019 :: Published 29 April 2019

Starban Lingkungan XI Kecamatan Medan Polonia.

Wardani, N. E. K. (2012). GAMBARAN PENGETAHUAN DAN PERILAKU PERSONAL HYGIENE ALAT KELURAHAN BENOWO SURABAYA, 01(Xi), 21-26. Retrieved from http://repository.uksw.edu/bitstre am/123456789/9041/8/T1_46200 9021 Judul.pdf 